\title{
BIOMATHEMATICAL ANALYSIS FOR THE CARBON NANOTUBES EFFECTS ON THE STAGNATION POINT FLOW TOWARDS A NONLINEAR STRETCHING SHEET WITH HOMOGENEOUS- HETEROGENEOUS REACTION
}

\author{
S. R. R. Reddy ${ }^{1}$, P. B. A. Reddy ${ }^{1}$ *
}

${ }^{1}$ Department of Mathematics, School of Advanced Sciences, VIT University, Vellore-632014, India

*Corresponding author Email: pbarmaths@gmail.com

\begin{abstract}
:
The main objective of this paper is to study the homogeneous-heterogeneous reactions on magnetohydrodynamic flow over a nonlinear stretching sheet.Water/blood is taken as the base fluid for the suspension of single-wall carbon nanotubes. The governing non-linear partial differential equations are transformed into ordinary differential equations which are solved numerically by utilizing the fourth order Runge-Kutta method with shooting technique. Graphical results have been presented for the velocity, temperature, concentration, local skin friction coefficient and local Nusselt number for various physical parameters of interest. Comparisons with previously published data are performed and the results are found to be excellent agreement.
\end{abstract}

Keywords:Magnetic field,homogeneous and heterogeneous reactions, stagnation point flow, viscous dissipation etc.

\section{NOMENCLATURE}

\begin{tabular}{|c|c|c|c|}
\hline$x, y$ & space coordinates & $S c$ & Schmidt number \\
\hline$u, v$ & velocity components & $S$ & suction parameter \\
\hline$c_{p}$ & specific heat capacity & SWCNT & single wall carbon nanotube \\
\hline$u_{e}$ & free stream velocity & & \\
\hline$D_{A}, D_{B}$ & diffusion coefficients & \multicolumn{2}{|c|}{ Greek symbols } \\
\hline$k^{*}$ & Rosseland mean absorption coefficient & $\delta$ & ration of mass diffusion coefficient \\
\hline$T$ & fluid temperature & $\phi$ & nanoparticle volume fraction \\
\hline M & magnetic parameter & $v$ & kinematic viscosity \\
\hline$A$ & ratio of free stream velocity & $\sigma$ & electrical conductivity \\
\hline $\mathrm{Nr}$ & radiation conduction parameter & $\rho$ & density \\
\hline$p r$ & Prandtl number & $\alpha$ & thermal diffusivity \\
\hline$K$ & $\begin{array}{l}\text { strength of the homogenous reactions } \\
\text { parameter }\end{array}$ & $\eta$ & local similarity variable \\
\hline$k$ & thermal conductivities & $\sigma^{*}$ & Stefan-Boltzmann constant \\
\hline Ec & Eckert number & $\psi$ & stream function \\
\hline$Q$ & heat source parameter & Subscripts & \\
\hline$q_{r}$ & the radiative heat flux & $f$ & fluid \\
\hline$K_{s}$ & strength of the heterogeneous reaction & $n f$ & nanofluid \\
\hline
\end{tabular}




\section{Introduction}

Hydromagnetic stagnation point flows with thermal effects have large number of applications in the natural phenomena, engineering and industrial processes. A stagnation point is a point in a flow field where the local velocity of the fluid is zero. It was mentioned by Clancy (1975) that the existence of stagnation points is very apparent on the surface of objects in the flow field, in which the object is responsible for reducing the fluid velocity to zero. Stagnation point exists in the flows which may be symmetric or asymmetric, viscous or inviscid, normal or oblique, forward or reverse, two-dimensional or three-dimensional, steady or unsteady, homogeneous or two immiscible fluids (Weidman and Putkaradze, 2003)). The flow near a stagnation point has an important bearing on several technological processes. Such processes are cooling of nuclear reactors during emergency shutdown, heat exchangers placed in a law-velocity environment, blood flow problems, textile and paper industries, the aerodynamics extrusion of plastic sheets, cooling of electronic devices by fans, solar central receivers exposed to wind currents, the cooling of an infinite metallic plate in a cooling bath and many hydrodynamic processes. Bachok et al. (2013) explored the boundary layer stagnation-point flow toward a stretching or shrinking sheet in a nanofluid and found that dual solutions exist only for the shrinking case. Soid et al. (2017) investigated the axisymmetric stagnation-point flow over a stretching or shrinking vertical surface with a second-order velocity slip. Dashet et al. (2016) studied two-dimensional laminar boundary layer stagnation point flow of a viscous incompressible electrically conducting fluid towards a linearly varying stretching/shrinking taking into account chemical reaction of diffusing species and internal heat generation/absorption. Mahapatra and Gupta (2002) reported heat transfer in stagnation-point flow towards a stretching sheet. Srinivas et al. (2015) investigate the effect of chemical reaction and stagnation point flow on an unsteady flow of a micropolar fluid over a stretching sheet.

The purpose here is to advance the stagnation point flow of nanofluid towards a stretching sheet into five directions. Firstly, to examine melting heat transfer. Secondly to predict the impact of homogeneousheterogeneous reactions. Thirdly to analyze the porous space features. Fourth to investigate CNTs (single wall and multi wall carbon nanotubes) effects for different base fluids. Fifth to consider nonlinear stretching sheet with variable thickness. The term nano wasfirst introduced by Choi (1995). Choi declared that an advanced approach for thermal enhancement is obtained by utilizing nanoscale pieces in the base fluids (like water, ethylene glycol, kerosene etc.). Shiekholeslami and Ellahi(2015) discussed magnetohydrodynamic (MHD) three-dimensional mesoscopic simulation on convection of nanofluid. Khan et al. (2014) studied the fluid flow and heat transfer phenomenon in the flow of carbon nanotubes and Navier slip condition. Turkyilmazoglu(2015) discussed analytical solution and heat transfer phenomena of nanofluid in the single and multi-phase models. Ding et al. (2006) investigated the heat transfer behavior of CNT nanofluids flowing through a horizontal tube. Some of the authors (Sheikholeslami and Rokni, 2017, Reddy, 2016, Sheikholeslami and Rokni, 2017, Hamad and Ferdows, 2012, Suneetha and Reddy, 2016, Cortell, 2007, Khan et. al. 2017, Ramzan and Bilal, 2017) discussed the effects of nanoparticles for boundary layer flow over a stretching or shrinking surface.

Chemical reactions involve both homogeneous and heterogeneous reactions, with examples occurring in the combination, catalysis and biochemical systems. Some of the reactions have the ability to proceed very slowly are not at all, except in the presence of a catalyst. Some of the common applications of chemical reactions are fog formation and dispersion, ceramics and polymer products, food processing and hydrometallurgical industry. Hayat et al. (2015) examine the stagnation point flow of carbon nanotubes with homogeneous-heterogeneous reactions along a cylinder with Newtonian heating. Imtiaz et al. (2016) addresses the homogeneousheterogeneous reactions in MHD flow of viscous fluid flow by a curved stretching surface. The isothermal model for homogeneous heterogeneous reactions in the boundary layer flow was investigated by Merkin (1996). Reddy and Suneetha (2017) analyzed the effect of homogeneous-heterogeneous chemical reaction on the MHD stagnation point flow over a stretching/shrinking surface in a porous medium.

Literature survey indicates that most of the researchers investigated the characteristic of nanofluid over a stretching sheet using the $\mathrm{Cu}, \mathrm{CoFe}_{2} \mathrm{O}_{4}, \mathrm{Ti}, \mathrm{Ag}, \mathrm{Al}_{2} \mathrm{O}_{3}$ nanoparticles. The characteristics of SWCNTs suspended in the water/blood induced by stretching sheet with homogeneous-heterogeneous reactions are not explored until now. Thus, our main purpose is to analyze the behavior of base fluids water and blood with SWCNT by nonlinear stretching sheet. 


\section{Mathematical Formulation}

Consider a two-dimensional stagnation point flow of nanofluid by an impermeable nonlinear stretching or shrinking sheet. The sheet is stretched with non-linear velocity $u_{w}(x)=c x^{m}$, where $c$ is a constant for which $c>0$ corresponds to the stretching sheet and $c<0$ for shrinking sheet and $m$ is a power index and wall mass suction velocity is $v=v_{w}(x)$ with $v_{w}<0$ for suction and $v_{w}>0$ for injection respectively. The pressure gradient and external forces are neglected. By keeping the origin fixed and the $x$-axis is taken along the stretching sheet in the direction of the motion and the $y$-axis is taken perpendicular to the sheet in the outward direction towards the fluid of ambient temperature $T_{\infty}$ as $y \rightarrow \infty$. A non-uniform transverse magnetic field of strength $B(x)=B_{0} x^{(m-1) / 2}$ is applied in the transverse direction, where $B_{0}$ is the constant related to magnetic field and $m(\neq-1)$ is a power law exponent. SWCNT's are used as nanoparticles and water/blood is taken as a base fluid. The heat produced is neglected throughout the irreversible chemical reaction. HomogeneousHeterogeneous reactions of two chemical species A and B are also considered. For cubic autocatalysis, the homogeneous reaction is

$A+2 B \rightarrow 3 B$ Rate $=k_{1} a b^{2}$,

while first-order isothermal reaction on the catalyst surface is represented in the form

$A \rightarrow B$ Rate $=k_{s} a$,

Here $a$ and $b$ are the concentrations of chemical species $A$ and $B$ while $k_{1}$ and $k_{s}$ are the rate constants. The equations of the reaction ensure that the reaction rate is zero at the external flow and at the outer edge of the boundary layer. The continuity, momentum, energy and concentration equations under the boundary layer approximations are given by:

$\frac{\partial u}{\partial x}+\frac{\partial v}{\partial y}=0$

$u \frac{\partial u}{\partial x}+v \frac{\partial u}{\partial y}=u_{e} \frac{d u_{e}}{d x}+v_{n f} \frac{\partial^{2} u}{\partial y^{2}}+\frac{\sigma B^{2}(\mathrm{x})}{\rho_{n f}}\left(u_{e}-u\right)$

$u \frac{\partial T}{\partial x}+v \frac{\partial T}{\partial y}=\alpha_{n f} \frac{\partial^{2} T}{\partial y^{2}}-\frac{1}{\left(\rho c_{p}\right)_{n f}} \frac{\partial q_{r}}{\partial y}+\frac{\mu_{n f}}{\left(\rho c_{p}\right)_{n f}}\left(\frac{\partial u}{\partial y}\right)^{2}+\frac{Q_{0}}{\left(\rho c_{p}\right)_{n f}}\left(T-T_{\infty}\right)$

$u \frac{\partial a}{\partial x}+v \frac{\partial a}{\partial y}=D_{A} \frac{\partial^{2} a}{\partial y^{2}}-k_{1} a b^{2}$

$u \frac{\partial b}{\partial x}+v \frac{\partial b}{\partial y}=D_{B} \frac{\partial^{2} b}{\partial y^{2}}+k_{1} a b^{2}$

The appropriate boundary conditions are:

$$
\begin{aligned}
& u=u_{w}(x)= \pm c x^{m}, v=v_{w}, T=T_{w}(x)=\mathrm{T}_{\infty}+c_{1} x^{n}, D_{A} \frac{\partial a}{\partial y}=k_{s} a, D_{B} \frac{\partial b}{\partial y}=-k_{s} \text { a at } y=0 \\
& u \rightarrow u_{e}(x)=c_{\infty} x^{m}, T \rightarrow T_{\infty}, a \rightarrow a_{0}, b \rightarrow 0 \text { as } y \rightarrow \infty
\end{aligned}
$$

In the above expressions $u$ and $v$ denote the velocity components in the $x$-direction and $y$-direction respectively, $u_{e}$ is the free stream velocity, $v_{n f}$ is the kinematic viscosity of the Nano fluid, $\sigma$ is the electrical conductivity of fluid, $\rho_{n f}$ is the density of the nanofluid, $\alpha_{n f}$ is the thermal diffusivity of the nanofluid, $\mu_{n f}$ is the coefficient of dynamic viscosity of the nanofluid, $\left(\rho c_{p}\right)_{n f}$ is the heat capacitance of the nanofluid, $T$ is the fluid temperature, $D_{A}$ and $D_{B}$ are the diffusion coefficients of the $A$ and $B$.

Thermophysical models of carbon nanotubes are:

$$
\mu_{n f}=\frac{\mu_{f}}{(1-\phi)^{2.5}}, v_{n f}=\frac{\mu_{n f}}{\rho_{n f}}, \rho_{n f}=(1-\phi) \rho_{f}+\phi \rho_{C N T},
$$


$\alpha_{n f}=\frac{k_{n f}}{\left(\rho c_{P}\right)_{n f}}, \frac{K_{n f}}{K_{f}}=\frac{(1-\phi)+2 \phi \frac{k_{C N T}}{K_{C N T}-K_{f}} \ln \frac{K_{C N T}+K_{f}}{2 k_{f}}}{(1-\phi)+2 \phi \frac{k_{f}}{k_{C N T}-k_{f}} \ln \frac{k_{C N T}+k_{f}}{2 k_{f}}}$

where $\mu_{n f}$ is the viscosity of nanofluid, $\phi$ is the nanoparticle volume fraction, $\rho_{f}$ and $\rho_{C N T}$ are the density of the fluid and solid particles respectively and $k_{f}, k_{C N T}$ are the thermal conductivities of fluid and nanoparticles respectively. Thermal radiation is simulated using the Rosseland diffusion approximation and in accordance with this, the radiative heat flux $q_{r}$ is given by

$q_{r}=-\frac{4 \sigma^{*}}{3 k^{*}} \frac{\partial T^{4}}{\partial y}$,

where $\sigma^{*}$ is the Stefan-Boltzmann constant and $k^{*}$ is the Rosseland mean absorption coefficient. If the temperature differences within the mass of blood flow are sufficiently small, then Eq. (10) can be linearized by expanding $T^{4}$ into the Taylor's series about $T_{\infty}$, and neglecting higher-order terms, we get

$T^{4} \cong 4 T_{\infty}^{3} T-3 T_{\infty}^{4}$

\subsection{Method of solution}

We introduce the following similarity transformations are defined as follows

$\eta=\left(\frac{(m+1) u_{w}(x)}{2 v_{f} x}\right)^{1 / 2} y, \psi=\left(\frac{2 v_{f} x u_{w}(x)}{m+1}\right)^{1 / 2} f(\eta), \theta(\eta)=\frac{T-T_{\infty}}{T_{w}-T_{\infty}}, g(\eta)=\frac{a}{a_{0}}, h(\eta)=\frac{b}{b_{0}}$

where, $v_{f}$ is the kinematic viscosity of the fluid and $\psi$ is the stream function, define as $u=\frac{\partial \psi}{\partial y}, v=-\frac{\partial \psi}{\partial x}$

which is identically satisfies the Eq. (3). Substituting Eqs. (9)-(12) in (4)-(8), we obtain the following nonlinear ordinary differential equations:

$$
\begin{aligned}
& \left(\frac{1}{(1-\phi)^{2.5}}\right) f^{\prime \prime \prime}+\left(1-\phi+\phi \frac{\rho_{C N T}}{\rho_{f}}\right)\left(f f^{\prime \prime}-\frac{2 m}{m+1}\left(\left(f^{\prime}\right)^{2}-A^{2}\right)\right)-M \frac{2}{m+1}\left(f^{\prime}-A\right)=0 \\
& \left(\frac{1}{p r}\left(\frac{k_{n f}}{k_{f}}+\frac{4}{3} N r\right)\right) \theta^{\prime \prime}+\left(1-\phi+\phi \frac{\left(\rho c_{p}\right)_{C N T}}{\left(\rho c_{p}\right)_{f}}\right)\left(f \theta^{\prime}-\frac{2 n}{m+1} f^{\prime} \theta\right)+\frac{E c}{(1-\phi)^{2.5}} f^{\prime \prime 2}+\frac{2 Q}{m+1} \theta=0, \\
& \frac{1}{S c} g^{\prime \prime}+f g^{\prime}-\frac{2 K}{m+1} g h^{2}=0 \\
& \frac{\delta}{S c} h^{\prime \prime}+f h^{\prime}+\frac{2 K}{m+1} g h^{2}=0
\end{aligned}
$$

The boundary conditions take the form

$$
\begin{aligned}
& f(0)=S, f^{\prime}(0)= \pm 1, \theta(0)=1, g^{\prime}(0)=\sqrt{\frac{2}{m+1}} K_{s} g(0), \delta h^{\prime}(0)=-\sqrt{\frac{2}{m+1}} K_{s} g(0) \\
& f^{\prime}(\infty) \rightarrow A, \theta(\infty) \rightarrow 0, g(\infty) \rightarrow 1, h(\infty) \rightarrow 0
\end{aligned}
$$

$M$ is the magnetic parameter, $A$ is the ratio of free stream velocity $c_{\infty}$ to stretching/shrinking velocity $c, N r$ is the radiation conduction parameter, $p r$ is the Prandtl number, $K$ is the strength of the homogenous reactions parameter, $E c$ is the Eckert number, $Q$ is the heat source parameter, $K_{s}$ is the strength of the heterogeneous reaction parameter, $\delta$ is the ration of mass diffusion coefficients and $S c$ is the Schmidt number. Sis the suction parameter $(S>0)$. These quantities are defined as follows:

$$
A=\frac{c_{\infty}}{c}, \mathrm{M}=\frac{\sigma B_{0}^{2}}{c \rho_{f}}, \mathrm{pr}=\frac{v_{f}}{\alpha_{f}}, N r=\frac{4 \sigma^{*} T_{\infty}^{3}}{k^{*} k_{f}}, E c=\frac{u_{w}^{2}}{\left(T_{w}-T_{\infty}\right)\left(c_{p}\right)_{f}}, Q=\frac{x Q_{0}}{u_{w}\left(\rho c_{p}\right)_{f}},
$$




$$
S=-\frac{v_{w}}{x^{(m-1) / 2}} \sqrt{\frac{2}{c(m+1) v_{f}}}, K=\frac{k_{1} b_{0}^{2} x}{u_{w}}, K_{s}=\frac{k_{s}}{D_{A}} \sqrt{\frac{x v_{f}}{u_{w}}}, S c=\frac{v_{f}}{D_{A}}, \delta=\frac{D_{A}}{D_{B}}
$$

Here it is assumed that diffusion coefficients of chemical species $A$ and $B$ to be of a comparable size. This argument provides us to make further assumption that the diffusion coefficients $D_{A}$ and $D_{B}$ are equal i.e. $\delta$ $=1$.

$g(\eta)+h(\eta)=1$

Now Eqs. (15) and (16) yield

$g^{\prime \prime}+S c f g^{\prime}-\frac{2}{m+1} K S c g(1-g)^{2}=0$,

With the boundary conditions

$\mathrm{g}^{\prime}(0)=\sqrt{\frac{2}{\mathrm{~m}+1}} \mathrm{~K}_{\mathrm{s}} \mathrm{g}(0), \mathrm{g}(\eta) \rightarrow 1$ as $\eta \rightarrow \infty$,

Skin friction coefficient and local Nusselt number are defined as follows:

$$
\begin{aligned}
& C_{f}=\frac{\tau_{w}}{\rho_{f} u_{w}^{2}}, N u_{x}=\frac{x q_{w}}{k_{f}\left(T_{w}-T_{\infty}\right)}, \\
& \tau_{W}=\mu_{n f}\left(\frac{\partial u}{\partial y}\right)_{y=0}, q_{w}=-\left(k_{n f}+\frac{16 \sigma^{*} T_{\infty}^{3}}{3 k^{*}}\right)\left(\frac{\partial T}{\partial y}\right)_{y=0}
\end{aligned}
$$

Dimensionless skin friction coefficient and local Nusselt number are expressed as follows:

$C_{f} \mathrm{Re}_{x}^{1 / 2}=\frac{1}{(1-\phi)^{2.5}} \sqrt{\frac{m+1}{2}} f^{\prime \prime}(0), N u_{x} \mathrm{Re}_{x}^{-1 / 2}=-\sqrt{\frac{m+1}{2}}\left(\frac{k_{n f}}{k_{f}}+\frac{4}{3} N r\right) \theta^{\prime}(0)$

\section{Numerical Estimates and Related Discussion:}

The main objective of the present paper is to study the stagnation point flow and heat transfer of viscous incompressible nanofluids over a vertical stretching/shrinking sheet is considered. Eqs. (13), (14), (17), (20) and (21) have been numerically solved by utilizing the fourth order Runge-Kutta method with shooting technique. We illustrate various physical parameters viz the magnetic parameterMsuction parameter $S$, the radiation conduction parameter $N r$, Eckert number $E c$, nanoparticle volume friction $\phi$, ratio parameter $A$, strength of heterogeneous reaction parameter $K_{s}$, strength of homogeneous reaction parameter $K$, on the velocity $f^{\prime}$ and temperature $\theta$ and concentration $g$ for the base fluid water and blood. For numerical results, we considered $M=1.5, S=0.1, A=0.8, \phi=0.15, N r=0.5, E c=0.1, Q=0.5, K=0.2, K_{s}=0.1$

These values are conserved as common unless specifically pointed out in the appropriate graphs.

Fig. 1 and 2, show the velocity and temperature profiles for two types of nanofluids on stretching/shrinking sheets. From Fig. 1, we observed that the velocity for stretching and shrinking sheets starts from two opposite points but it reaches to same value at the end.

The velocity $f^{\prime}$ and temperature $\theta$ and concentration $g$ for both stretching and shrinking sheets for SWCNTblood are presented graphically in Figs. 3-10. Figs. 3 depicts the dimensionless velocity profile for various values of ratio parameter $(A)$. Here we noticed that velocity profile and boundary layer thickness increase with an increase in ratio parameter $(A>1)$ and for $A<1$ the boundary layer thickness has an opposite effect for stretching case. The velocity profile increases with an increase in the ratio parameter for shrinking sheet. It is also noticed that both the fluid and sheet move with the same velocity at $A=1$. The effect of suction parameters on the velocity has been plotted in Fig. 4. It is found that an increase in the suction parameter leads to increasing effect of velocity profile in shrinking sheet whereas the reverse trend is observed in stretching sheet.

Biomathematical analysis for the carbon nanotubes effects on the stagnation point flow towards a nonlinear stretching sheet... 


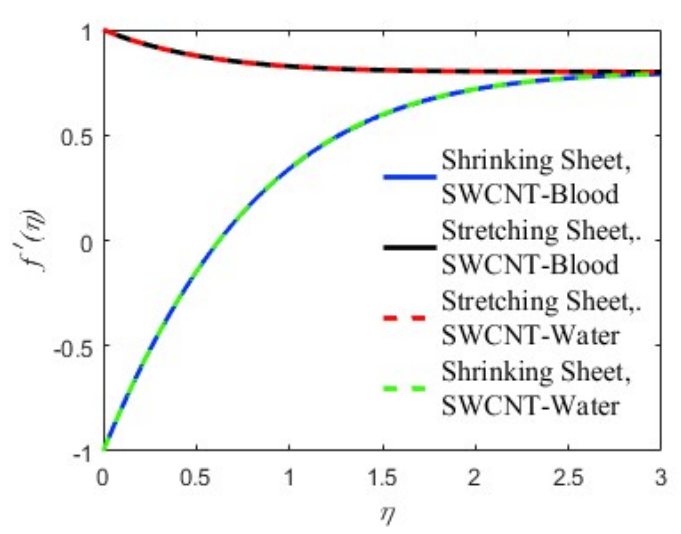

Fig. 1: Effect of blood/water-SWCNT on the velocity for shrinking, stretching sheets

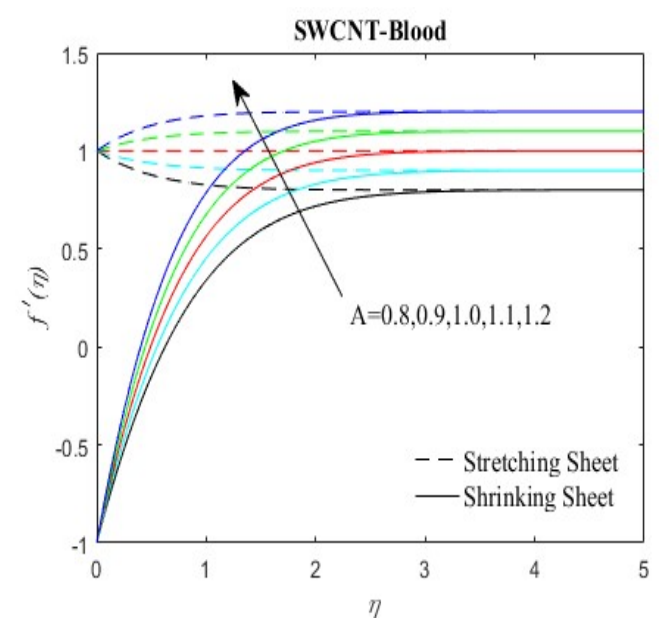

Fig. 3: Effect of ratio of free stream velocity $(A)$ on the velocity

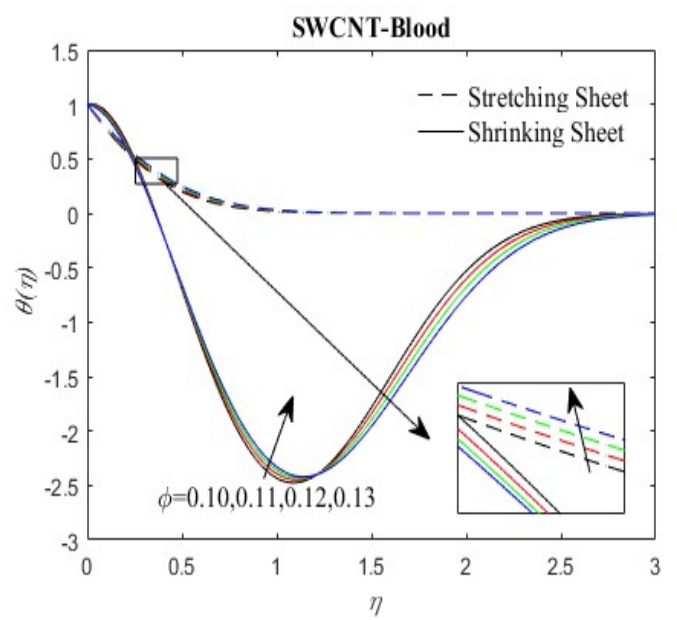

Fig. 5: Effect of nano particle volume fraction, $\phi$ on the temperature

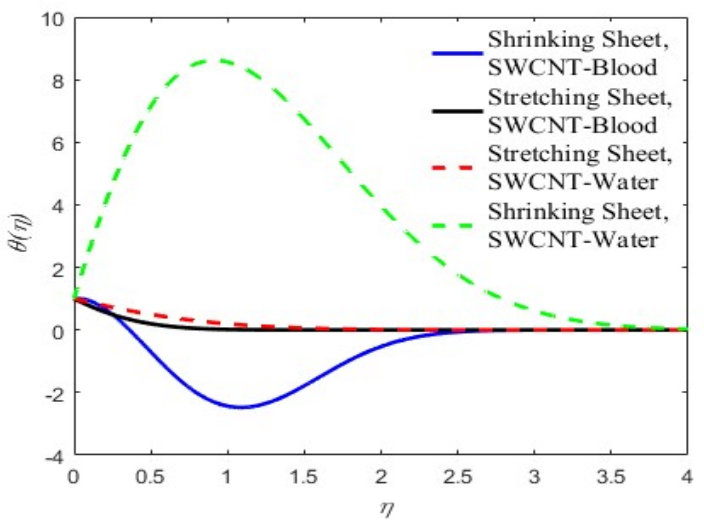

Fig. 2: Effect of blood/water-SWCNT on the temperature for shrinking, stretching sheets

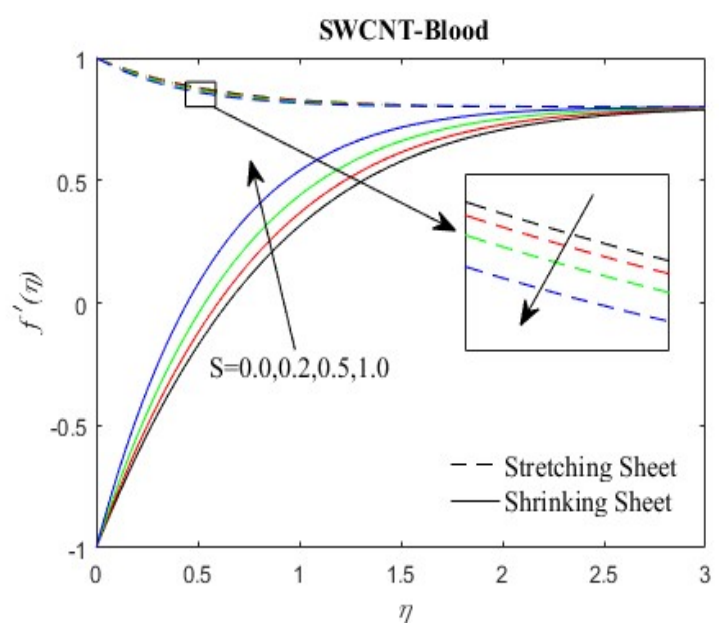

Fig. 4: Effect of suction parameter(S)on the velocity

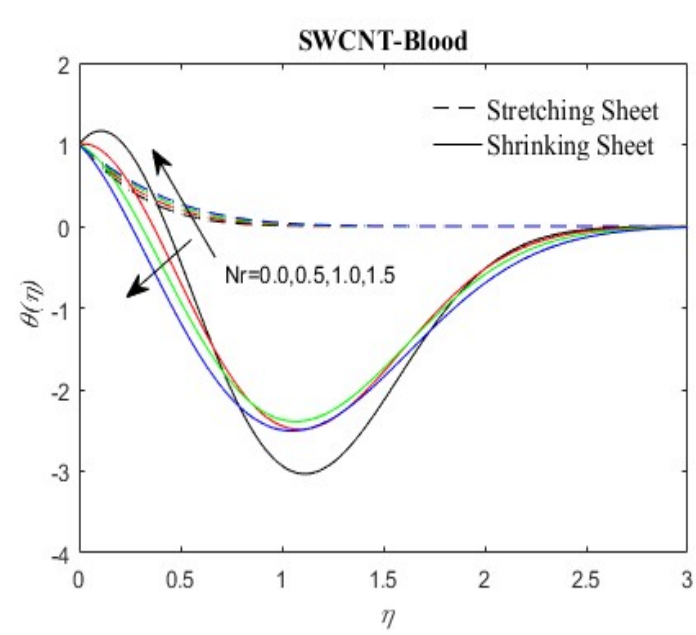

Fig. 6: Effect of radiation conduction parameter, $\mathrm{Nr}$ on the temperature 
S. R. R. Reddy, P. B. A. Reddy/ Journal of Naval Architecture and Marine Engineering, 17(2020) 67-77

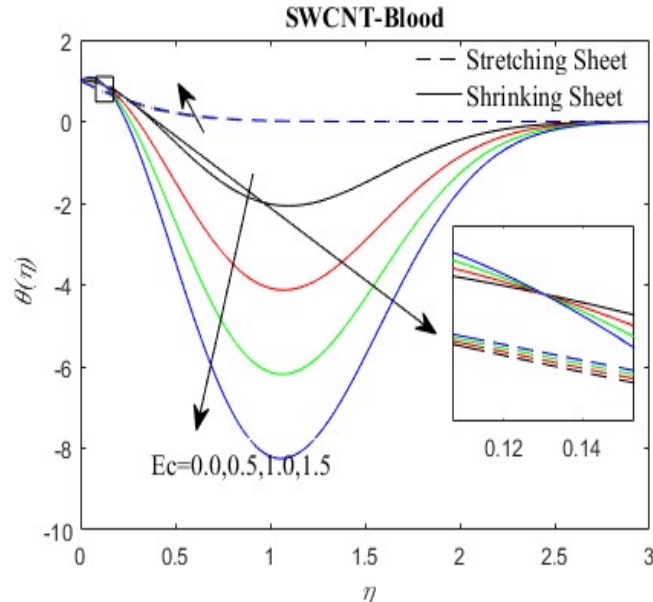

Fig. 7: Effect of Eckert number, Econ the temperature

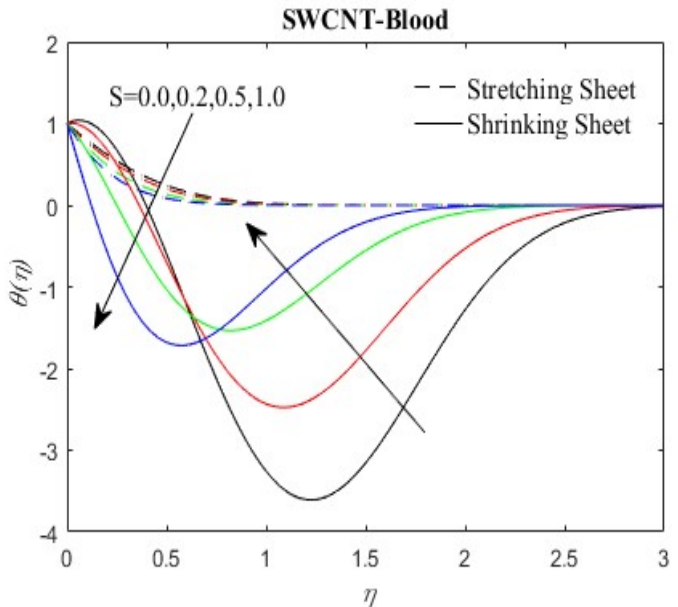

Fig. 8: Effect of suction parameter, $S$ on the temperature

Fig. 5 demonstrates the effect of Nano particle volume fraction on the temperature. The temperature profile is enhanced for the larger values of Nano particle volume fraction for stretching case, while the opposite trend is observed for shrinking case in the interval $\eta=[0,0.5] \cup[1.2,3]$. Influence of the radiation conduction parameter on the temperature is displayed in Fig.6. Large values of radiation conduction parameter lead to enhance the temperature profile for stretching case whereas the reverse trend is observed in shrinking sheet. Fig. 7 demonstrates the effect of Eckert number on the temperature for both stretching and shrinking cases. For the stretching case, it is observed that the temperature increases as Eckert number increases and the reverse trend is observed in shrinking cases. We also found that the temperature have positive temperature gradient for stretching sheet, while the opposite trend is observed for the shrinking sheet. Fig. 8 shows the effect of suction parameter on the temperature. It is interesting to note that temperature gradient decreases with increasing suction parameter of shrinking rate near the sheet but the reverse effect is observed a little far off the sheet. The temperature decreases with increasing the suction parameter. Influence of strength of homogeneous reaction on the concentration is displayed in Fig.9. As the boundary layer thickness increases for higher values of strength of homogeneous reaction parameter, the concentration increases for both stretching and shrinking sheets.

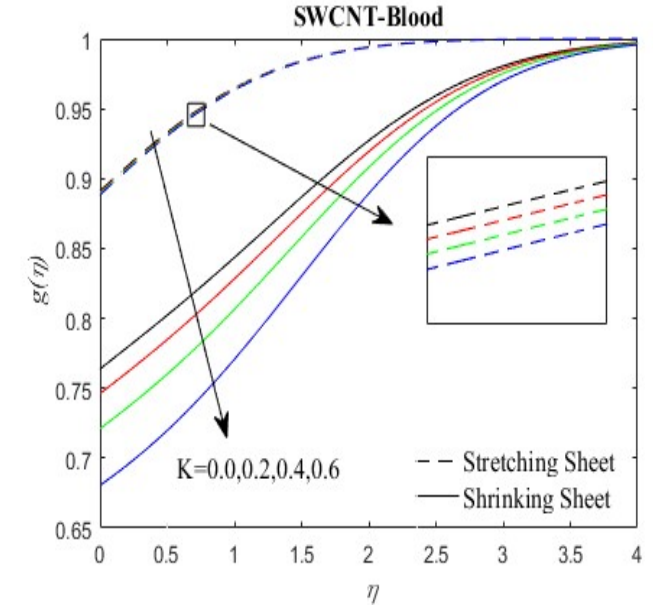

Fig. 9: Effect of strength of homogeneous reaction, $K$ on the concentration

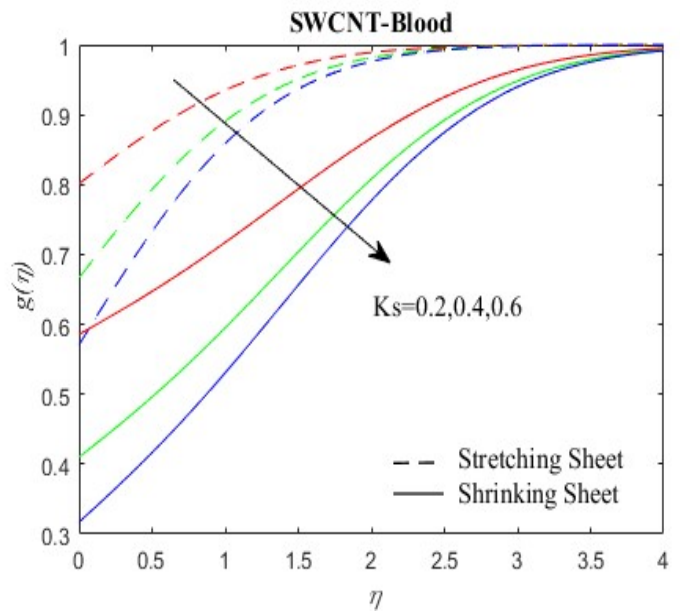

Fig. 10: Effect of strength of heterogeneous reaction, $K s$ on the concentration 
S. R. R. Reddy, P. B. A. Reddy/ Journal of Naval Architecture and Marine Engineering, 17(2020) 67-77

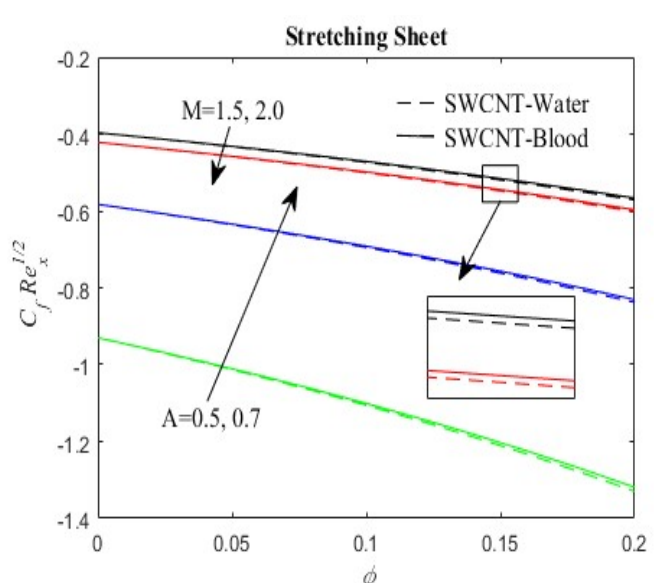

Fig. 11: The variation of skin friction coefficient against magnetic, volume fraction and ratio parameters in the case of stretching sheet.

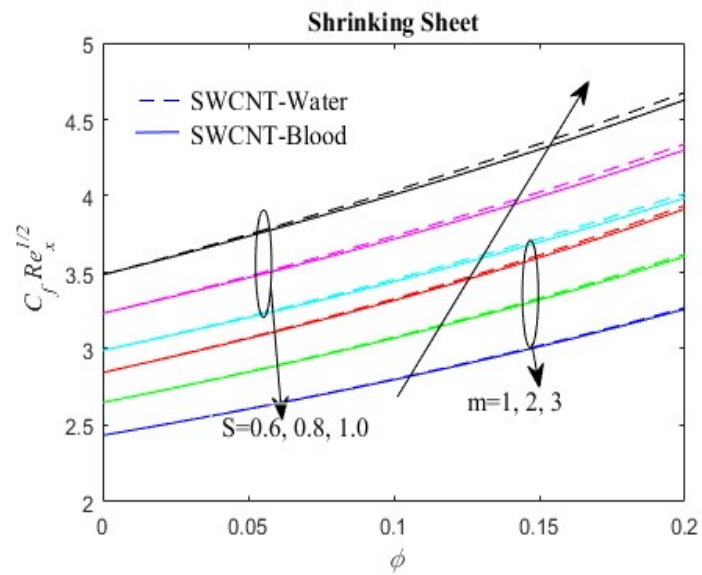

Fig. 13: The variation of skin friction coefficient against volume fraction, suction and nonlinearity parameters in the case of shrinking sheet.

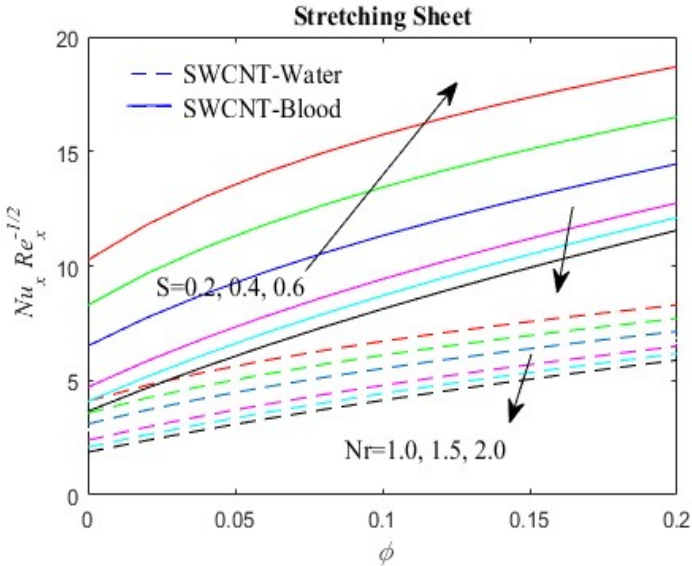

Fig. 15: The variation of local Nusselt number against suction, volume fraction and radiation conduction parameter.

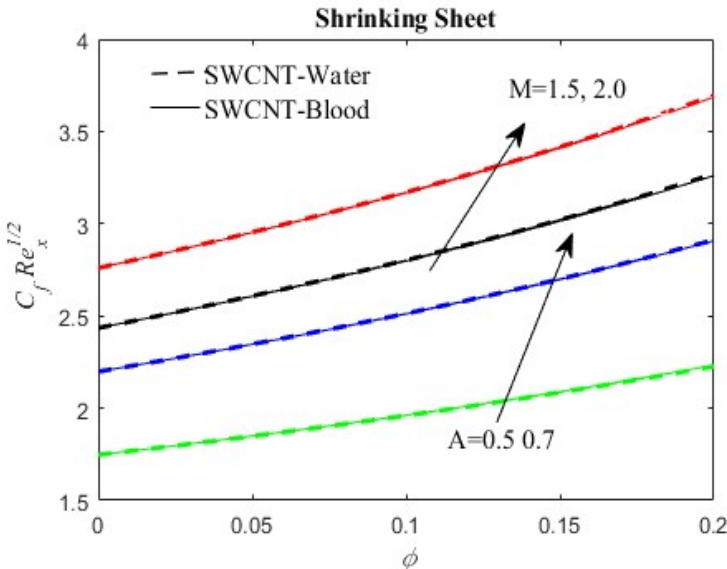

Fig. 12: The variation of skin friction coefficient against magnetic, volume fraction and ratio parameters in the case of shrinking sheet.

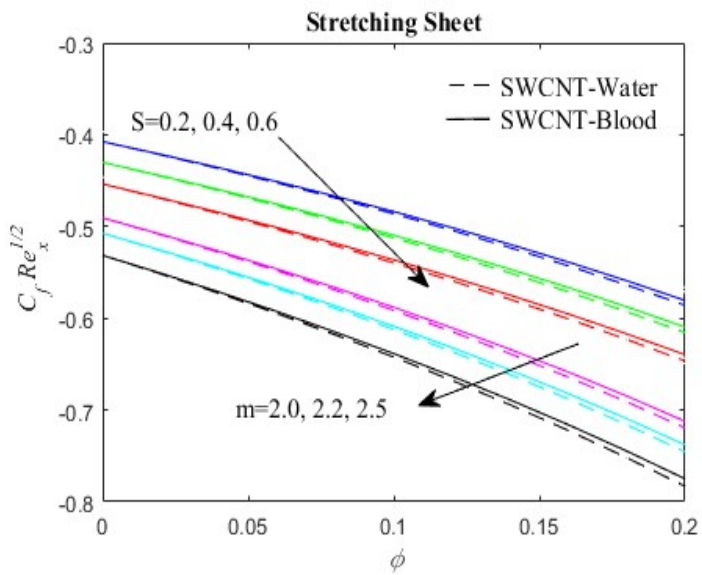

Fig. 14: The variation of skin friction coefficient against volume fraction, suction and nonlinearity parameters in the case of stretching sheet.

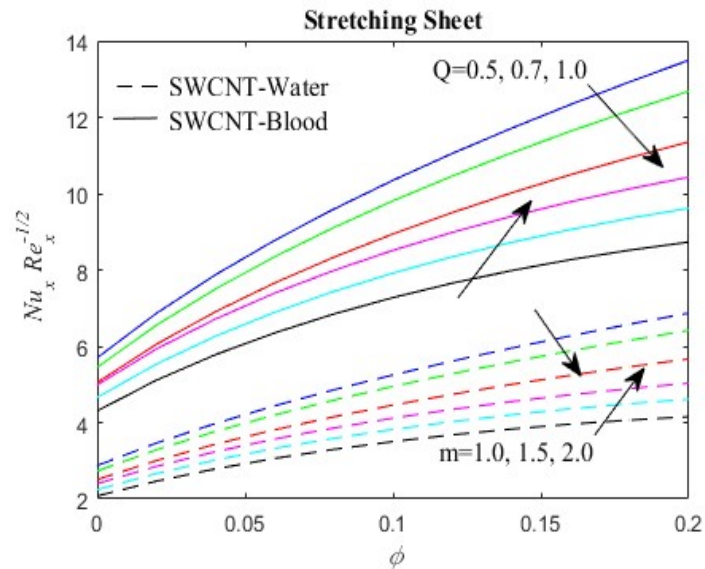

Fig. 16: The variation of local Nusselt number against heat source, volume fraction, and nonlinearity parameter. 
S. R. R. Reddy, P. B. A. Reddy/ Journal of Naval Architecture and Marine Engineering, 17(2020) 67-77

The effect of strength of heterogeneous reaction on the concentration is shown in Fig .10. For higher $K s$ values, the concentration decreases near the surface of sheet for both stretching and shrinking sheets. Concentration distribution is lower in shrinking sheet when compared to stretching sheet. Skin friction coefficient and local Nusselt number for both stretching and shrinking sheets for two types of nanofluids namely SWCNT-water and SWCNT-blood are presented graphically in Figs. 11-16, when the nanoparticle volume fraction is in the range of $0 \leq \phi \leq 0.2$. Fig. 11 illustrates the effect of magnetic, volume fraction and ratio parameters on local skin friction coefficient. Higher values of ratio parameter result in the enhancement of local skin friction coefficient while it decreases for large values of magnetic parameter for both SWCNT-water and SWCNT-blood in stretching sheet. Fig. 12 shows the effect of magnetic, volume fraction and ratio parameters on local skin friction coefficient. Higher values of magnetic, and ratio parameters result in the enhancement of local skin friction coefficient for both SWCNT-water and SWCNT-blood in shrinking sheet. The effect of volume fraction, suction and nonlinearity parameters on the local skin friction coefficient has been plotted in Fig. 13. It is found that an increase in the suction parameter and non-linear parameter leads to increasing effect of absolute local skin friction coefficient for both SWCNT-water and SWCNT-blood in shrinking sheet. The effect of the volume fraction, suction and nonlinearity parameters on local skin friction coefficient is shown in Fig. 14. It is evident from this plot that the local skin friction coefficient decreases with increasing the suction parameter and non-linear parameter for both SWCNT-water and SWCNT-blood in stretching sheet.

Table 1: Numerical values of thermophysical properties of base fluid and nanoparticles

\begin{tabular}{llll}
\hline Physical properties & Base fluids & Nanoparticle \\
\cline { 2 - 4 } & water & Blood & SWCNT \\
\hline$\rho\left(k g / \mathrm{m}^{3}\right)$ & 997.1 & 1063 & 2600 \\
$C_{p}(\mathrm{~J} / \mathrm{kg} K)$ & 4179 & 3594 & 425 \\
$k(W / m K)$ & 0.613 & 0.492 & 6600 \\
\hline
\end{tabular}

Table 2: Comparison of $-f^{\prime \prime}(0)$ with Mahapatra and Gupta (2002) and Hamad and Ferdows (2012) for various values of $A$ when $p r=5.0, N r=M=R i=Q=\phi=0$.

\begin{tabular}{|c|c|c|c|c|c|}
\hline$A$ & $\begin{array}{ll}\text { Mahapatra } & \text { and } \\
\text { Gupta (2002) } & \end{array}$ & Present Results & $m$ & $\begin{array}{l}\text { Hamad and Ferdows } \\
(2012)\end{array}$ & $\begin{array}{l}\text { Present } \\
\text { Results }\end{array}$ \\
\hline 0.1 & 0.9694 & 0.969386 & 0.5 & 0.889544 & 0.889544 \\
\hline 0.2 & 0.9181 & 0.918107 & 1.0 & 1.000000 & 1.000000 \\
\hline 0.5 & 0.6673 & 0.667264 & 3.0 & 1.148593 & 1.148593 \\
\hline
\end{tabular}

Table 3: Comparison of $-\theta^{\prime}(0)$ with Cortell (2007) for various values of $m$ when $p r=5.0$, $N r=M=R i=Q=\phi=0$.

\begin{tabular}{lllll}
\hline$m$ & $-\theta^{\prime}(0)$ & & $-\theta^{\prime}(0)$ & \\
& $P r=1, E c=0$ & & $P r=1, E c=0.1$ & \\
\cline { 2 - 5 } & Cortell (2007) & Present & Cortell (2007) & Present \\
& & Results & 1.219985 & Results \\
\hline 0.75 & 1.252672 & 1.252701 & 1.219940 \\
1.5 & 1.439393 & 1.439375 & 1.662506 & 1.405184 \\
7.00 & 1.699298 & 1.699318 & & 1.662599 \\
\hline
\end{tabular}

Fig. 15 depicts the variation of local Nusselt number for various values of suction, volume fraction and radiation conduction parameter. The local Nusselt number decreases with increase of radiation conduction parameter whereas the reverse trend is observed with suction parameter for both SWCNT-water and SWCNT-blood in stretching sheet. The effect of heat source, volume fraction, and nonlinearity parameter on the local Nusselt number has been plotted in Fig. 16. Higher values of nonlinear parameter result in the enhancement of local Nusselt number while it decreases for large values of heat source parameter for both SWCNT-water and SWCNT-blood in stretching sheet. Thermal physical properties of the base fluid (density, specific heat and 
S. R. R. Reddy, P. B. A. Reddy/ Journal of Naval Architecture and Marine Engineering, 17(2020) 67-77

thermal conductivity) and CNTs (SWCNT) are presented in Table 1. For the accuracy and validity, we compared the present numerical values corresponding to the $-f^{\prime \prime}(0)$ with that of Hamad and Ferdows (2012) Mahapatra and Gupta (2002) (Table 2). Moreover, Table 3 presents the numerical values corresponding to $-\theta^{\prime}(0)$ with the previously published numerical results of Cortell (2007).

\section{Conclusions}

Homogeneous-heterogeneous reactions in magnetohydrodynamic flow due to a nonlinear stretching sheet is inspected and observed the following conclusions:

- The velocity profile increases by increasing the ratio parameter or suction parameter for both stretching and shrinking sheets.

- The temperature profile enhances with increasing the radiation conduction parameter Eckert number, nanoparticle volume friction parameter for stretching sheet.

- The concentration profile decreases by increasing the strength of the homogenous and heterogeneous reactions parameters for both stretching and shrinking sheets.

- The skin friction coefficient increases with increasing the magnetic parameter in shrinking case while the opposite trend is observed for stretching case.

- The local Nusselt number decreases with increasing the suction and radiation conduction parameter for stretching sheet.

\section{References}

Bachok, N., Ishak A. and Pop I. (2013): Boundary layer stagnation-point flow toward a stretching/shrinking sheet in a nanofluid, ASME J. Heat Transf. Vol. 135, pp. 054501. https://doi.org/10.1115/1.4023303

Chaudhary, M. A. and Merkin, J. H. (1995): A Simple Isothermal Model for Homogeneous-Heterogeneous Reactions in Boundary-Layer Flow-I: Equal Diffusivities, Fluid Dyn. Vol. 16, No. 6, pp. 311-333. https://doi.org/10.1016/0169-5983(95)00015-6

Choi, S. U. S. (1995): Enhancing thermal conductivity of fluids with nanoparticles, developments and applications of non-Newtonian flows, ASME-Publications-Fed, Vol. 23, pp. 99-105.

Clancy, L. J. (1975): Aerodynamics, Pitman.

Cortell, R. (2007): Viscous flow and heat transfer over a nonlinearly stretching sheet, Appl. Math Comput. Vol. 184, pp. 864-873. https://doi.org/10.1016/j.amc.2006.06.077

Dash, G. C., Tripathy, R. S., Rashidi, M. M. and Mishra, S. R. (2016): Numerical approach to boundary layer stagnation-point flow past a stretching/shrinking sheet, Journal of Molecular Liquids, Vol. 221, pp. 860-866.

https://doi.org/10.1016/j.molliq.2016.06.072

Ding, Y.,Alias, H., Wen, D. and Williams, R. A. (2006): Heat transfer of aqueous suspensions of carbon nanotubes (CNT nanofluids), Int. J. Heat Mass Transf. Vol. 49, pp. 240-250.

https://doi.org/10.1016/j.ijheatmasstransfer.2005.07.009

Hamad, M. A. A. and Ferdows, M. (2012): Similarity solutions to viscous flow and heat transfer of nanofluid over non-linearly stretching sheet, Appl. Math. Mech. Vol. 33, No. 7, pp. 923-930.

https://doi.org/10.1007/s10483-012-1595-7

Hayat, T., Farooq, M. and Alsaedi, A. (2015): Homogenous-heterogeneous reactions in the stagnation point flow of carbon nanotubes with Newtonian heating, AIP Advances, Vol. 5, pp. 027130-1-18.

https://doi.org/10.1063/1.4908602

Imtiaz, M., Hayat, T., Alsaedi, A. and Hobiny, A. (2016): Homogeneous-heterogeneous reactions in MHD flow due to an unsteady curved stretching surface, Journal of Molecular Liquids, Vol. 221, pp. 245-253.

https://doi.org/10.1016/j.molliq.2016.05.060

Khan, W. A., Khan, Z. H. and Rahi, M. (2014): Fluid flow and heat transfer of carbon nanotubes along a flat plate with Navier slip boundary, Appl. Nano Sci. Vol. 4, pp. 633-641. https://doi.org/10.1007/s13204-013-0242$\underline{9}$

Khan, Z. H., Qasim, M., Haq, R. U. and Al-Mdallal,Q. M. (2017): Closed form dual nature solutions of fluid flow and heat transfer over a stretching/shrinking sheet in a porous medium, Chinese Journal of Physics, Vol. 55, pp. 1284-1293. https://doi.org/10.1016/j.cjph.2017.07.001

Biomathematical analysis for the carbon nanotubes effects on the stagnation point flow towards a nonlinear stretching sheet... 
S. R. R. Reddy, P. B. A. Reddy/ Journal of Naval Architecture and Marine Engineering, 17(2020) 67-77

Mahapatra, T. R. and Gupta, A. (2002): Heat transfer in stagnation-point flow towards a stretching sheet, Heat Mass Trans. Vol. 38, pp. 517-521. https://doi.org/10.1007/s002310100215

Merkin, J. H. (1996): A model for isothermal homogeneous-heterogeneous reactions in boundary-layer flow, Math. Computer Model. Vol. 24, pp. 125-136. $\underline{\mathrm{h}}$ https://doi.org/10.1016/0895-7177(96)00145-8

Ramzan, M. and Bilal, M. (2017): Jae Dong Chung, Radiative Williamson nanofluid flow over a convectively heated Riga plate with chemical reaction-A numerical approach, Chinese Journal of Physics, Vol. 000, pp. 1-11. https://doi.org/10.1016/j.cjph.2017.04.014

Reddy, P. B. A. and Suneetha S. (2017): Effects of homogeneous-heterogeneous chemical reaction and slip velocity on MHD stagnation flow of a micropolar fluid over a permeable stretching/shrinking surface embedded in a porous medium, Frontiers in Heat and Mass Transfer (FHMT), Vol. 8, No. 24, pp. 1-11. https://doi.org/10.5098/hmt.8.24

Reddy, P. B. A., Suneetha S. and Raju K. V. (2016): Boundary layer flow of a Maxwell Nano fluid over an exponential stretching surface with aligned magnetic field and convective boundary condition, Global Journal of Pure and Applied Mathematics, Vol. 12, No. 3, pp. 119-124.

Shiekholeslami, M. and Ellahi, R. (2015): Three-dimensional mesoscopic simulation of magnetic field effect on natural convection of nanofluid, Int. J. Heat Mass Transfer, Vol. 89, pp. 799-808. https://doi.org/10.1016/j.ijheatmasstransfer.2015.05.110

Sheikholeslami, M. and Rokni, H. B. (2017): Effect of melting heat transfer on nanofluid flow in existence of magnetic field considering Buongiorno Model, Chinese Journal of Physics, Vol. 55, pp. 1115-1126. https://doi.org/10.1016/j.cjph.2017.04.019

Sheikholeslami, M. and Rokni, H.B. (2017): Influence of melting surface on MHD nanofluid flow by means of two phase model, Chinese Journal of Physics, Vol. 55, pp. 1352-1360. https://doi.org/10.1016/j.cjph.2017.06.008

Soid, S. K., Merkin, J., Ishak, A. and Pop, I. (2017): Axisymmetric stagnation point flow and heat transfer due to a stretching/shrinking vertical plate with surface second-order velocity slip, Meccanica, Vol. 52, pp. 139-151. https://doi.org/10.1007/s11012-016-0409-z

Srinivas, S., Reddy, P. B. A. and Prasad, B. S. R. V. (2014): Effects of chemical reaction and thermal radiation on MHD flow over an inclined permeable stretching surface with nonuniform heat source/sink an application to the dynamics of blood flow, Journal of Mechanics in Medicine and Biology, Vol. 14, No. 5, pp. 1450067-1-24. https://doi.org/10.1142/S0219519414500675

Srinivas, S., Reddy, P. B. A. and Prasad B. S. R. V. (2015): Non-Darcian unsteady flow of a micropolar fluid over a porous stretching sheet with thermal radiation and chemical reaction, Heat Transfer-Asian Research, Vol. 44, No. 2, pp. 172-187. https://doi.org/10.1002/htj.210900

Suneetha, S. and Reddy, P. B. A. (2016): Investigation on graphene nanofluids and its applications: a brief literature review, Research J. Pharm. and Tech. Vol. 9, No. 6, pp. 655-663. https://doi.org/10.5958/0974360X.2016.00124.4

Turkyilmazoglu, M. (2015): Analytical solutions of single and multi-phase models for the condensation of nanofluid film flow and heat transfer, Eur. J. Mech. - B/Fluids, Vol. 53, pp. 272-277. https://doi.org/10.1016/j.euromechflu.2015.06.004

Weidman, P. D. and Putkaradze, V. (2003): Axisymmetric stagnation flow obliquely impinging on a circular cylinder, Eur. J. Mech. B/Fluids Vol. 22, pp. 123-131. https://doi.org/10.1016/S0997-7546(03)00019-0 